\title{
DEMOGRAPHIC INFLUENCES ON BASELINE AND DERIVED SCORES FROM THE TRAIL MAKING TEST IN HEALTHY OLDER AUSTRALIAN ADULTS
}

\author{
Robert L. Hester ${ }^{1,2}$, Glynda J. Kinsella ${ }^{3}$, Ben Ong ${ }^{1}$, and \\ Jodie McGregor ${ }^{1}$ \\ ${ }^{1}$ School of Psychological Science, La Trobe University, Melbourne, Victoria, \\ Australia, ${ }^{2}$ Trinity College Institute of Neuroscience, Trinity College, Dublin, \\ Ireland, and ${ }^{3}$ Department of Psychology, Caulfield General Medical Centre, \\ Melbourne, Victoria, Australia
}

Normative data from 363 community-dwelling older adults (60-89 years) is presented in relation to performance on the Trail Making Test. Age and years of education were identified as significantly impacting on performance. Therefore, data are presented for four separate age groups (60-69; 70-74; 75-79; 80-89) and two different lengths of education. In addition to data for Trails $A$ and $B$, information is provided for the difference and ratio scores, which are increasingly used by clinicians to interpret executive function.

\section{INTRODUCTION}

The influence of demographic variables on cognitive test performance has proved crucial to the reliability and validity of clinical neuropsychology assessment (Lezak, 1995), and screening for cognitive impairment relies heavily on the reliability of the available normative database with which to compare a client's test performance. This is particularly important when assessing older adults for whom age-related changes in cognition need to be taken account of before identifying disease-related impairment. The Trail Making Test (TMT) (Reitan, 1955; Reitan \& Wolfson, 2001) is a brief, easily administered, and inexpensive screening tool consisting of two conditions: Trail Making Part A (TMT-A) and Trail Making Part B (TMT-B). TMT-B has been frequently used as an index of cognitive flexibility or set-shifting, an important aspect of executive attention control (Arbuthnott \& Frank, 2000; Horton, 1979; Kortte, Horner, \& Windham, 2002; Moll, Oliveira-Souza Rd, Moll, Bramati, \& Andreiuolo, 2002). The TMT has been demonstrated to be sensitive to cognitive impairment in a range of agerelated clinical conditions, including Parkinson disease (Goldman, Baty, Buckles,

Address correspondence to: Glynda Kinsella School of Psychological Science, La Trobe University, Melbourne, Victoria 3086, Australia. Tel.: +61 039479 2409. Fax: +61 039479 1956. g.kinsella@ latrobe.edu.au

Accepted for publication: June 2, 2004. 
Sahrmann, \& Morris, 1998; Pillon et al., 1995), Alzheimer's disease (Chen et al., 2000, 2001), and other dementias (Hestad, Aukrust, Ellertsen, \& Klove, 1996; Heun, Papassotiropoulos, \& Jennssen, 1998; Lunn et al., 1991; Paul et al., 2001; Selnes et al., 1991).

The recent finding of the TMT's sensitivity to the preclinical changes of Alzheimer's disease (Chen et al., 2000, 2001) has highlighted the need for normative data derived from large samples of healthy older adults. In this respect, although several recent studies have outlined the effect of age on TMT performance (Amodio et al., 2002; Drane, Yuspeh, Huthwaite, \& Klingler, 2002; Roberts \& Horton, 2002; Sherrill-Pattison, Donders, \& Thompson, 2000), the influence of education, particularly in normal aging samples, has received less coverage. The extensive normative data within the Mayo's Older Americans Normative Studies (Ivnik, Malec, Smith, \& Tangalos, 1996) provides education-based normative data; however, $84 \%$ of this large sample were reported to be highly educated (12 or more years of formal education). Richardson and Marottoli (1996) argued that this factor may limit the usefulness of the data for clinicians testing older adults, as the typical educational attainment for the current cohort of older Americans is less than 12 years. In a sample of 101 older adults, Richardson and Marottoli provide normative data adjusted for education level and, as expected, reported that older adults with less than 12 years education were significantly poorer on neuropsychological test performance (including the TMT) than older adults with higher levels of completed education. Furthermore, a recent large study by Tombaugh (2004) reported that performance on TMT-A and TMT-B is affected by both age and education; impact of education is especially significant for adults over 54 years of age.

However, neither the Halstead-Reitan Neuropsychological Battery norms (Heaton, Grant, \& Matthews, 1991) nor Richardson and Marottoli (1996), Ivnik et al. (1996), and Tombaugh (2004) report TMT normative data for the difference (TMT-B minus TMT-A) or ratio (TMT-B divided by TMT-A) derived scores that have been demonstrated as sensitive indices for detecting executive function impairments (Lamberty, Chatel, Bieliauskas, \& Linas, 1994; Ratti, Bo, Giardini, \& Soragna, 2002; Stuss et al., 2001). These derived scores borrow from the agerelated slow down of information processing concept used by other authors (Maylor \& Patrick, 1994; Perfect \& Maylor, 2000; Rogers \& Monsell, 1995) and calculate executive processing by first removing the time taken to perform the underlying or baseline condition. These test measures have been shown in some reports of TMT performance to provide better correlations with other measures of cognitive flexibility or executive functioning (Arbuthnott \& Frank, 2000). This is relevant to the field of cognitive aging of executive function and the complexity of differential diagnosis in older adults who are suspected of demonstrating mild executive dysfunction, often associated with an early presentation of degenerative disorder.

Given the continuing interest in the use of the derived scores of the TMT (difference and ratio scores) as indexing components of executive functioning, the aim of the present study was to examine the influence of age, education, and gender on all indices of TMT performance, including the derived scores, and provide normative data that reflected these demographic influences for a sample of healthy older adults. 


\section{METHOD}

\section{Participants}

Data for the present study was collected as part of a series of investigations at La Trobe University School of Psychological Science evaluating cognitive aging in older adults. All participants were living independently in metropolitan Melbourne, recruited via community organizations (e.g., swimming clubs, Rotary clubs), places of employment, experimenter networks, and by word-of-mouth to participate in studies examining prospective remembering in older adults. Participants were excluded on the basis of a premorbid history of neurological disorder, psychiatric illness, drug abuse or current use of psychoactive medication, or a Mini Mental State examination score less than 25 (Folstein, Folstein, \& McHugh, 1975). The sample comprised 363 participants between 60 and 89 years of age $(M=71.66$ years, $S D=6.96$ ). Male to female ratio was $135: 228$, which reflected a longer life expectancy for Australian females than for their male counterparts (Australian Bureau of Statistics, 1996). The mean years of education were $11.42(S D=3.21)$, which is lower than the sample mean of 14.1 years of education reported in the Mayo's Older Americans Normative Studies project (Ivnik et al., 1996).

\section{Materials and Procedure}

Participants were administered a battery of neuropsychological measures that included the TMT. Standard procedures for both TMT-A and TMT-B were administered to all 363 participants (Spreen \& Strauss, 1998). TMT-A is a timed test that requires subjects to draw lines to connect 25 consecutively numbered circles. TMT-B is also timed and requires subjects to connect consecutive numbers and letters, alternating between the two sequences (i.e., 1-A-2-B-3-C...L-12). The total score for both parts of the test were calculated based on the number of seconds required to complete the task. During the administration of both parts, errors were pointed out by the examiner and participants were redirected to the last correct circle while timing continued. Errors made by a participant are therefore reflected in their total score, rather than as a separate index (Reitan \& Wolfson, 1992). Mean scores for TMT-A and TMT-B were calculated together with difference (TMT-B minus TMT-A) and ratio (TMT-B divided by TMT-A) scores.

\section{RESULTS}

The demographic data for the sample is presented in Table 1. An initial treatment of the data investigated the influence of demographic variables, age, gender, and education on various measures derived from the TMT. A series of standard multiple regression analyses examined whether demographic variables significantly influenced performance on TMT-A and TMT-B and whether these variables affected the difference and ratio scores. The variables were entered simultaneously and the semipartial correlations are presented in Table 2.

The results of the multiple regression analyses indicated that gender had a significant but small influence on performance of TMT-A, accounting for only $1 \%$ of variance, thus supporting Ivnik et al.'s (1996) claim that gender corrections are not 
Table 1 Demographic characteristics of the sample

\begin{tabular}{|c|c|c|c|c|c|c|c|}
\hline \multirow[b]{3}{*}{ Group } & \multirow[b]{3}{*}{$N$} & \multicolumn{6}{|c|}{ Demographic variables } \\
\hline & & \multicolumn{2}{|c|}{ Age (years) } & \multicolumn{2}{|c|}{ Education (years) } & \multicolumn{2}{|c|}{ Gender } \\
\hline & & $M$ & $S D$ & $M$ & $S D$ & Male & Female \\
\hline $60-69$ & 130 & 65.7 & 2.6 & 11.8 & 3.2 & 82 & 48 \\
\hline $70-74$ & 106 & 72.0 & 1.4 & 11.1 & 3.2 & 39 & 67 \\
\hline $75-79$ & 79 & 76.7 & 1.4 & 10.8 & 3.0 & 31 & 48 \\
\hline $80-89$ & 48 & 83.2 & 3.2 & 11.9 & 3.0 & 17 & 31 \\
\hline Total sample & 363 & 72.3 & 6.4 & 11.4 & 3.2 & 135 & 228 \\
\hline
\end{tabular}

generally necessary in provision of normative data. Given the significant and more substantial contribution of age to performance of the TMT, performance was divided into four age-groups: 60-69 years, 70-74 years, 75-79 years, and 80-89 years for provision of normative data. These age group categories were selected to allow comparison to the previously published American norms for older adults performance on the TMT (Ivnik et al., 1996; Tombaugh, Rees, \& McIntyre, 1998). Education provided a significant influence on performance of TMT-B and the ratio and difference scores; therefore, it was decided that the normative data on all variables of the TMT would be uniformly corrected for education (see Tables 3-6).

To examine the generalizability of our normative data to populations outside Australia, we compared our data with those from Tombaugh (2004) (see Table 7). Their sample was chosen because it provided recent data from a large, education-stratified U.S. population with similar demographic characteristics to our own. For the

Table 2 Summary of multiple regression analyses with gender, education and age predicting each of the TMT measures $(N=363)$

\begin{tabular}{|c|c|c|c|c|c|}
\hline Task & Predictor(s) & $B$ & $S E B$ & $\beta$ & $s r^{2}$ \\
\hline \multicolumn{6}{|c|}{ Part A } \\
\hline & Age & 1.07 & 0.17 & $.319^{* *}$ & .103 \\
\hline & Education & -0.52 & 0.32 & -.078 & \\
\hline & Sex & 4.87 & 2.20 & $.110^{*}$ & .013 \\
\hline \multicolumn{6}{|c|}{ Part B } \\
\hline & Age & 2.26 & 0.33 & $.327^{* *}$ & .113 \\
\hline & Education & -2.91 & 0.67 & $-.211^{* *}$ & .050 \\
\hline & Sex & 6.21 & 4.41 & .068 & \\
\hline \multicolumn{6}{|c|}{ Difference score } \\
\hline & Age & 1.19 & 0.27 & $.219^{* *}$ & .051 \\
\hline & Education & -2.39 & 0.54 & $-.222^{* *}$ & .052 \\
\hline & Sex & 1.31 & 3.47 & .018 & \\
\hline \multicolumn{6}{|c|}{ Ratio Score } \\
\hline & Age & 0.00 & .00 & .003 & \\
\hline & Education & -0.35 & .01 & $-.134^{* *}$ & .017 \\
\hline & Sex & -0.97 & .09 & -.056 & \\
\hline
\end{tabular}

Note. ${ }^{*} p<.05 ;{ }^{* *} p<.01$. 
Table 3 Normative data for the TMT-Part A performance of an Australian sample aged 60 to 89 years, further subdivided by education

\begin{tabular}{|c|c|c|c|c|c|c|c|c|c|c|c|c|}
\hline \multirow[b]{2}{*}{ Age (years) } & \multicolumn{4}{|c|}{ Total sample } & \multicolumn{4}{|c|}{ Education $\leq 11$ years } & \multicolumn{4}{|c|}{ Education $\geq 12$ years } \\
\hline & $n$ & $M$ & $S D$ & $95 \% C I$ & $n$ & $M$ & $S D$ & $95 \% C I$ & $n$ & $M$ & $S D$ & $95 \% C I$ \\
\hline $60-69$ & 130 & 40.1 & 16.1 & $37-43$ & 65 & 43.6 & 17.5 & $38-49$ & 65 & 36.7 & 14.0 & $32-42$ \\
\hline $70-74$ & 106 & 43.9 & 16.9 & $41-47$ & 68 & 44.6 & 17.7 & $40-49$ & 38 & 42.9 & 15.7 & $36-49$ \\
\hline $75-79$ & 79 & 50.4 & 21.9 & $46-55$ & 53 & 51.3 & 24.4 & $46-57$ & 26 & 48.6 & 15.9 & $41-56$ \\
\hline $80-89$ & 48 & 57.9 & 33.4 & $48-68$ & 25 & 67.8 & 42.0 & $59-76$ & 23 & 47.3 & 15.1 & $40-56$ \\
\hline
\end{tabular}

purposes of the comparison, our 60-69-years-old sample $(M=65.7)$ and $80-89$ years-old sample $(M=83.2)$ were compared to Tombaugh's 65-69-years-old sample $(M=67.1)$ and 80-84-years-old sample $(M=81.8)$, respectively (see Table 7$)$. A series of independent group $t$ tests compared the mean performance of the Australian sample to the U.S. sample on both of the TMT indices, indicating only two significant differences (at $p<.01$ ) for TMT-B in the 60-69-years-old comparison and 80-89years-old comparison for subjects with greater than 12 years of education. Given the discrepancy in the 60-69 age range for TMT-B, we also compared the current sample to normative data from Drane et al. (2002) $(n=36, M=105.2, S D=41.1)$ and Tombaugh et al. (1998) $(n=61, M=81.2 ; S D=38.5)$, neither of which were significantly different to the current sample.

\section{DISCUSSION}

In relation to the baseline measures of the TMT (TMT-A and TMT-B), the results of the present study support previous findings regarding the influence of demographic variables on performance of the TMT (Amodio et al., 2002; Drane et al., 2002; Horton \& Roberts, 2001; Roberts \& Horton, 2002; Sherrill-Pattison et al., 2000). Age accounted for a significant amount of variance in performance for both TMT-A and TMT-B in our healthy older adult sample. The minimal but significant influence of gender on TMT performance in the present study is not unprecedented (Ivnik et al., 1996; Yeudall, Reddon, Gill, \& Stefanyk, 1987). However, it would appear that the influence was limited to psychomotor speed, as only TMT-A performance was significantly predicted by gender. In addition, our results indicated that TMT-B was influenced by a

Table 4 Normative data for the TMT-Part B performance of an Australian sample aged 60 to 89 years, further subdivided by education

\begin{tabular}{|c|c|c|c|c|c|c|c|c|c|c|c|c|}
\hline \multirow[b]{2}{*}{ Age (years) } & \multicolumn{4}{|c|}{ Total sample } & \multicolumn{4}{|c|}{ Education $\leq 11$ years } & \multicolumn{4}{|c|}{ Education $\geq 12$ years } \\
\hline & $n$ & $M$ & $S D$ & $95 \% C I$ & $n$ & $M$ & $S D$ & $95 \% C I$ & $n$ & $M$ & $S D$ & $95 \% C I$ \\
\hline $60-69$ & 130 & 92.4 & 33.4 & $85-99$ & 65 & 103.4 & 35.6 & $93-114$ & 65 & 81.5 & 27.2 & $73-90$ \\
\hline $70-74$ & 106 & 104.0 & 48.2 & $96-112$ & 68 & 106.3 & 47.8 & $96-117$ & 38 & 101.7 & 49.7 & $90-113$ \\
\hline $75-79$ & 79 & 118.5 & 39.4 & $109-128$ & 53 & 121.7 & 40.0 & $110-134$ & 26 & 112.2 & 38.0 & $98-126$ \\
\hline $80-89$ & 48 & 131.4 & 52.5 & $119-143$ & 25 & 156.4 & 56.6 & $139-173$ & 23 & 104.2 & 29.7 & 89-119 \\
\hline
\end{tabular}


Table 5 Normative data for the TMT-difference score performance of an Australian sample aged 60 to 89 years, further subdivided by education

\begin{tabular}{|c|c|c|c|c|c|c|c|c|c|c|c|c|}
\hline \multirow[b]{2}{*}{ Age (years) } & \multicolumn{4}{|c|}{ Total sample } & \multicolumn{4}{|c|}{ Education $\leq 11$ years } & \multicolumn{4}{|c|}{ Education $\geq 12$ years } \\
\hline & $n$ & $M$ & $S D$ & $95 \% C I$ & $n$ & $M$ & $S D$ & $95 \% C I$ & $n$ & $M$ & $S D$ & $95 \% C I$ \\
\hline $60-69$ & 130 & 52.3 & 26.9 & $46-58$ & 65 & 59.8 & 28.8 & $51-68$ & 65 & 44.8 & 22.8 & $37-52$ \\
\hline $70-74$ & 106 & 60.7 & 39.9 & $54-67$ & 68 & 61.8 & 38.0 & $53-70$ & 38 & 58.8 & 43.5 & $49-69$ \\
\hline $75-79$ & 79 & 68.2 & 30.0 & $61-76$ & 53 & 70.4 & 29.2 & $61-80$ & 26 & 63.5 & 30.6 & $52-75$ \\
\hline $80-89$ & 48 & 73.4 & 41.5 & $64-83$ & 25 & 88.6 & 48.7 & $74-102$ & 23 & 56.8 & 23.4 & $44-69$ \\
\hline
\end{tabular}

small but significant effect of education, which is consistent with the more general effect of this variable on executive function (Daigneault \& Braun, 1993; Fisk \& Warr, 1996; Keys \& White, 2000; Schretlen et al., 2000; Van der Linden, Beerten, \& Pesenti, 1998; West, 2001). The influence of education was of particular interest due to the relative absence of education-adjusted normative data in the literature. The results support the findings of Richardson and Marottoli (1996) who found, after dividing their older adult sample into education-based groups (greater than or less than 12 years of education), significant discrepancies in TMT-B performance of adults aged 75 years and older. Tombaugh (2004) also indicated a significant influence of education on TMT-B, accounting for $38 \%$ of the variance in performance, although this effect was negated by controlling for age with only $2 \%$ of the variance in their $18-89$-years-old sample subsequently accounted for.

However, the derived difference and ratio scores minimize the impact of demographic variables on performance estimates. Education continues to be a significant factor when interpreting test performance, especially in the difference score. In contrast, the comparatively reduced age effect in the difference score and the absence of an age-related decline in the ratio score is notable. The derived scores are intended to more closely approximate estimates of executive function, specifically set-switching, by removing baseline features of performance on the trails such as motor speed and visual scanning speed. There is evidence to suggest that the ratio score provides a stronger correlation with other measures of set-switching than other TMT measures (Arbuthnott \& Frank, 2000; Lamberty, 1994). Given both of these results, the use of this derivative score, rather than the constituent TMT-A or TMT-B performances,

Table 6 Normative data for the TMT - ratio score performance of an Australian sample aged 60 to 89 years, further subdivided by education

\begin{tabular}{|c|c|c|c|c|c|c|c|c|c|c|c|c|}
\hline \multirow[b]{2}{*}{ Age (years) } & \multicolumn{4}{|c|}{ Total sample } & \multicolumn{4}{|c|}{ Education $\leq 11$ years } & \multicolumn{4}{|c|}{ Education $\geq 12$ years } \\
\hline & $n$ & $M$ & $S D$ & $95 \% C I$ & $n$ & $M$ & $S D$ & $95 \% C I$ & $n$ & $M$ & $S D$ & $95 \% C I$ \\
\hline $60-69$ & 130 & 2.43 & 0.80 & $2.29-2.58$ & 65 & 2.49 & 0.79 & $2.30-2.69$ & 65 & 2.37 & 0.82 & $2.15-2.60$ \\
\hline $70-74$ & 106 & 2.49 & 1.01 & $2.33-2.65$ & 68 & 2.49 & 0.84 & $2.30-2.68$ & 38 & 2.48 & 1.27 & $2.19-2.77$ \\
\hline $75-79$ & 79 & 2.47 & 0.70 & $2.29-2.66$ & 53 & 2.51 & 0.71 & $2.31-2.73$ & 26 & 2.39 & 0.69 & $2.03-2.74$ \\
\hline $80-89$ & 48 & 2.43 & 0.73 & $2.20-2.67$ & 25 & 2.56 & 0.81 & $2.25-2.87$ & 23 & 2.30 & 0.61 & $1.93-2.68$ \\
\hline
\end{tabular}


Table 7 Comparison of TMT-A and TMT-B normative scores between the current Australian and Tombaugh et al. (2004) U.S. samples, further subdivided by education

\begin{tabular}{|c|c|c|c|c|c|c|c|c|c|c|c|c|}
\hline \multirow[b]{3}{*}{ Age (years) } & \multicolumn{4}{|c|}{ Total sample } & \multicolumn{4}{|c|}{ Education $\leq 11$ years } & \multicolumn{4}{|c|}{ Education $\geq 12$ years } \\
\hline & \multicolumn{2}{|c|}{ Current } & \multicolumn{2}{|c|}{ Tombaugh } & \multicolumn{2}{|c|}{ Current } & \multicolumn{2}{|c|}{ Tombaugh } & \multicolumn{2}{|c|}{ Current } & \multicolumn{2}{|c|}{ Tombaugh } \\
\hline & $n$ & $M$ & $n$ & $M$ & $n$ & $M$ & $n$ & $M$ & $n$ & $M$ & $n$ & $M$ \\
\hline \multicolumn{13}{|l|}{ TMT-A } \\
\hline $60-69$ & 130 & 40.1 & 97 & 36.5 & 65 & 43.6 & 65 & 39.1 & 65 & 36.7 & 32 & 33.8 \\
\hline $70-74$ & 106 & 43.9 & 106 & 41.3 & 68 & 44.6 & 76 & 42.5 & 38 & 42.9 & 30 & 40.1 \\
\hline $75-79$ & 79 & 50.4 & 108 & 46.3 & 53 & 51.3 & 74 & 50.8 & 26 & 48.6 & 34 & 41.7 \\
\hline $80-89$ & 48 & 57.9 & 118 & 56.7 & 25 & 67.8 & 84 & 58.2 & 23 & 47.3 & 34 & 55.3 \\
\hline \multicolumn{13}{|l|}{ TMT-B } \\
\hline $60-69$ & 130 & 92.4 & 97 & $79.2^{*}$ & 65 & 103.4 & 65 & 91.3 & 65 & 81.5 & 32 & $67.1^{*}$ \\
\hline $70-74$ & 106 & 104.0 & 106 & 98.1 & 68 & 106.3 & 76 & 109.9 & 38 & 101.7 & 30 & 86.2 \\
\hline $75-79$ & 79 & 118.5 & 108 & 115.6 & 53 & 121.7 & 74 & 130.6 & 26 & 112.2 & 34 & 100.7 \\
\hline $80-89$ & 48 & 131.4 & 118 & 142.4 & 25 & 156.4 & 84 & 152.7 & 23 & 104.2 & 34 & $132.1^{*}$ \\
\hline
\end{tabular}

Note. ${ }^{*}$ Represent significant differences between the two samples $(p<.01)$.

would present a useful strategy when attempting to tap this cognitive construct in a sample of variable age.

One caveat to the findings regarding the influence of demographic variables is that while age, education, and gender demonstrated significant effects on different indices of the TMT, the amount of variance explained was generally small, particularly for gender and education. While normative data have been provided with stratifications where the significant demographic influences were found, it is debatable whether this represents the most useful comparison for clinicians to refer to when examining patient data. As such, the larger sample cohorts, prior to stratification by gender and education, may represent the more appropriate comparison for reference. Comparisons between the current sample of healthy older Australians with Tombaugh's (2004) comprehensive U.S. sample revealed no statistical difference in TMT-A performance and two group differences in TMT-B performance, one in 60-69-year-olds and the other for 80-89-year-olds with more than 12 years education. However, in comparisons between the current sample and two other available sets of normative data (Drane et al., 2002; Tombaugh et al., 1998), these differences were not observed. The findings suggest that the current sample, including its derived indices, has generalizability beyond the Australian population.

The influence of demographic characteristics noted here also raises the issue of interpreting TMT performance and, more generally, executive function, in the context of a patient's intellectual history. Years of education was utilized as a relatively crude index of premorbid intellectual function in the present study; however, it would appear important for future studies providing normative data on executive tests to also administer other clinical measures to provide a more discrete measurement of premorbid functioning and to clarify the role of intellectual capacity in influencing a client's performance on widely used clinical neuropsychological measures of executive function. 
Overall, the present study confirms the influence of demographic characteristics on baseline performance of the TMT (TMT-A and TMT-B) in a healthy older adult sample; however, these demographic influences can be minimized when utilizing derived measures, difference and ratio scores aimed at more closely indexing components of executive function. Given this finding we have provided normative data tables for all common clinical indices of the TMT, adjusting for age and education, for a large sample of healthy older adults. While these stratifications have been provided, caution should be used by clinicians when deciding whether to utilize adjusted scores, since the influence of education, while significant, accounted for only small amounts of performance variability at the cost of considerable sample cell size reduction.

\section{ACKNOWLEDGMENTS}

The authors would like to thank Mirabella Stammers and psychology students at La Trobe University for assisting with data collection.

\section{REFERENCES}

Amodio, P., Wenin, H., Del Piccolo, F., Mapelli, D., Montagnese, S., Pellegrini, A., et al. (2002). Variability of Trail Making Test, Symbol Digit Test and Line Trait Test in normal people. A normative study taking into account age-dependent decline and sociobiological variables. Aging; Clinical and Experimental Research, 14(2), 117-131.

Arbuthnott, K. \& Frank, J. (2000). Trail Making Test, Part B as a measure of executive control: validation using a set-switching paradigm. Journal of Clinical \& Experimental Neuropsychology, 22(4), 518-528.

Austrialian Bureau of Statistics (2003). 2001 Census Basic Community Profile and Snapshot. http: www.abs.gov.au (2003; Nov 22).

Chen, P., Ratcliff, G., Belle, S. H., Cauley, J. A., DeKosky, S. T., \& Ganguli, M. (2000). Cognitive tests that best discriminate between presymptomatic $\mathrm{AD}$ and those who remain nondemented. Neurology, 55(12), 1847-1853.

Chen, P., Ratcliff, G., Belle, S. H., Cauley, J. A., DeKosky, S. T., \& Ganguli, M. (2001). Patterns of cognitive decline in presymptomatic Alzheimer disease: a prospective community study. Archives of General Psychiatry, 58(9), 853-858.

Daigneault, S. \& Braun, C. M. (1993). Working memory and the Self-Ordered Pointing Task: Further evidence of early prefrontal decline in normal aging. Journal of Clinical and Experimental Neuropsychology, 15(6), 881-895.

Drane, D. L., Yuspeh, R. L., Huthwaite, J. S., \& Klingler, L. K. (2002). Demographic characteristics and normative observations for Derived-Trail Making Test indices. Neuropsychiatry, Neuropsychology, \& Behavioral Neurology, 15(1), 39-43.

Fisk, J. E. \& Warr, P. (1996). Age and working memory: The role of perceptual speed, the central executive, and the phonological loop. Psychology and Aging, 11(2), 316-323.

Folstein, M. F., Folstein, S. E., \& McHugh, P. R. (1975). "Mini-Mental State": A practical method for grading the cognitive state of patients for the clinicians. Journal of Psychiatric Research, 12, 189-198.

Goldman, W. P., Baty, J. D., Buckles, V. D., Sahrmann, S., \& Morris, J. C. (1998). Cognitive and motor functioning in Parkinson disease: Subjects with and without questionable dementia. Archives of Neurology, 55(5), 674-680. 
Hestad, K., Aukrust, P., Ellertsen, B., \& Klove, H. (1996). Neuropsychological deficits in HIV-1 seropositive and seronegative intravenous drug users (IVDUs): A follow-up study. Journal of the International Neuropsychological Society, 2(2), 126-133.

Heun, R., Papassotiropoulos, A., \& Jennssen, F. (1998). The validity of psychometric instruments for detection of dementia in the elderly general population. International Journal of Geriatric Psychiatry, 13(6), 368-380.

Horton, A. M., Jr. (1979). Some suggestions regarding the clinical interpretation of the Trail Making Test. Clinical Neuropsychology, 1, 20-23.

Horton, A. M., Jr. \& Roberts, C. (2001). Derived Trail Making Test indices in a sample of substance abusers: Demographic effects. International Journal of Neuroscience, 111(1-2), 123-132.

Ivnik, R. J., Malec, J. F., Smith, G. E., \& Tangalos, E. G. (1996). Neuropsychological tests' norms above age 55: COWAT, BNT, MAE Token, WRAT-R Reading, AMNART, STROOP, TMT, and JLO. The Clinical Neuropsychologist, 10(3), 262-278.

Keys, B. A. \& White, D. A. (2000). Exploring the relationship between age, executive abilities, and psychomotor speed. Journal of the International Neuropsychological Society, 6(1), $76-82$.

Kortte, K. B., Horner, M. D., \& Windham, W. K. (2002). The Trail Making Test, part B: Cognitive flexibility or ability to maintain set? Applied Neuropsychology, 9(2), 106-109.

Lamberty, G. J. P., Chatel, S. H., Bieliauskas, D. M., \& Linas, A. (1994). Derived Trail Making Test indices: A preliminary report. Neuropsychiatry, Neuropsychology, \& Behavioral Neurology, 7(3), 230-234.

Lezak, M. D. (1995). Neuropsychological Assessment (3rd ed) New York: Oxford University Press.

Lunn, S., Skydsbjerg, M., Schulsinger, H., Parnas, J., Pedersen, C., \& Mathiesen, L. (1991). A preliminary report on the neuropsychologic sequelae of human immunodeficiency virus. Archives of General Psychiatry, 48(2), 139-142.

Maylor, E. A. R. \& Patrick M. A. (1994). Applying Brinley plots to individuals: Effect of aging on performance distributions in two speeded tasks. Psychology \& Aging, 9(2), 224-230.

Moll, J., Oliveira-Souza Rd, R., Moll, F. T., Bramati, I. E., \& Andreiuolo, P. A. (2002). The cerebral correlates of set-shifting: an fMRI study of the trail making test. Arquivos de Neuro-Psiquiatria, 60(4), 900-905.

Paul, R., Moser, D., Cohen, R., Browndyke, J., Zawacki, T., \& Gordon, N. (2001). Dementia severity and pattern of cognitive performance in vascular dementia. Applied Neuropsychology, 8(4), 211-217.

Perfect, T. J. \& Maylor, E. A. (2000). Models of cognitive aging. London: Oxford University Press.

Pillon, B., Gouider-Khouja, N., Deweer, B., Vidailhet, M., Malapani, C., Dubois, B., et al. (1995). Neuropsychological pattern of striatonigral degeneration: comparison with Parkinson's disease and progressive supranuclear palsy. Journal of Neurology, Neurosurgery and Psychiatry, 58(2), 174-179.

Ratti, M. T., Bo, P., Giardini, A., \& Soragna, D. (2002). Chronic alcoholism and the frontal lobe: Which executive functions are imparied? Acta Neurologica Scandinavica, 105(4), 276-281.

Reitan, R. M. (1955). Validity of the Trail Making Test to organic brain damage. Journal of Consulting Psychology, 19, 393-394.

Reitan, R. M. \& Wolfson, D. (1992). The Halstead-Reitan Neuropsychological Test Battery: Theory and clinical interpretation (2nd ed.). Tucson, AZ: Neuropsychology Press.

Reitan, R. M. \& Wolfson, D. (2001). The Halstead-Reitan Neuropsychological Test Battery: Research findings and clinical application. In A. S. Kaufman (Ed.), Specific learning 
disabilities and difficulties in children and adolescents: Psychological assessment and evaluation. New York: Cambridge University Press.

Richardson, E. D. \& Marottoli, R. A. (1996). Education-specific normative data on common neuropsychological indices for individuals older than 75 years. The Clinical Neuropsychologist, 10(4), 375-381.

Roberts, C. \& Horton, A. M., Jr. (2002). Derived Trail Making Test indices in a sample of alcohol abusers: Demographic effects. International Journal of Neuroscience, 112(3), 337-346.

Rogers, R. D. \& Monsell, S. (1995). Costs of a predictible switch between simple cognitive tasks. Journal of Experimental Psychology: General, 124(2), 207-231.

Schretlen, D., Pearlson, G. D., Anthony, J. C., Aylward, E. H., Augustine, A. M., Davis, A., et al. (2000). Elucidating the contributions of processing speed, executive ability, and frontal lobe volume to normal age-related differences in fluid intelligence. Journal of the International Neuropsychological Society, 6(1), 52-61.

Selnes, O. A., Jacobson, L., Machado, A. M., Becker, J. T., Wesch, J., Miller, E. N., et al. (1991). Normative data for a brief neuropsychological screening battery. Multicenter AIDS Cohort Study. Perceptual and Motor Skills, 73(2), 539-550.

Sherrill-Pattison, S., Donders, J., \& Thompson, E. (2000). Influence of demographic variables on neuropsychological test performance after traumatic brain injury. The Clinical Neuropsychologist, 14(4), 496-503.

Stuss, D. T., Bisschop, S. M., Alexander, M. P., Levine, B., Katz, D., \& Izukawa, D. (2001). The Trail Making Test: A study in focal lesion patients. Psychological Assessment, 13(2), 230-239.

Spreen, O. \& Strauss, S. (Eds) (1998). A compendium of neuropsychological tests: Administration, norms and commentary. (2nd ed.). Pp. 533-542. New York: Oxford University Press.

Tombaugh, T. N. (2004). Trail Making Test A and B: Normative data stratified by age and education. Archives of Clinical Neuropsychology, 19(2), 203-214.

Tombaugh, T. N., Rees, L., \& McIntyre, N. (1998). Normative data for the Trail Making Test. (Personal communication 1996. In O. Spreen \& S. Strauss (Eds.), A compendium of neuropsychological tests: Administration, norms, and commentary. (2nd ed.). New York: Oxford University Press.

Van der Linden, M., Beerten, A., \& Pesenti, M. (1998). Age-related differences in random generation. Brain and Cognition, 38(1), 1-16.

West, R. (2001). The transient nature of executive control processes in younger and older adults. European Journal of Cognitive Psychology, 13(1-2), 91-105.

Yeudall, L. T., Reddon, J. R., Gill, D. M., \& Stefanyk, W. O. (1987). Normative data for the Halstead-Reitan neuropsychological tests stratified by age and sex. Journal of Clinical Psychology, 43(3), 346-367. 